\section{A survey on relationships between thyroid hormone levels and clinical findings in dairy calf diarrhea}

\author{
Ali Hajimohammadi, \\ Abbas Roshan-Ghasrodashti,2 \\ Seyed Milad Forouzesh, ${ }^{3}$ Mehdi Saeb4 \\ 1Department of Clinical Sciences, School \\ of Veterinary Medicine, Shiraz University; \\ 2Department of Clinical Studies, School \\ of Veterinary Medicine, Islamic Azad \\ University, Kazerun; ${ }^{3}$ School of \\ Veterinary Medicine, Shiraz University; \\ 4Department of Basic Sciences, School of \\ Veterinary Medicine, Shiraz University, \\ Iran
}

\section{Abstract}

Calf diarrhea is an important disease that occurs in association with the interaction of various infectious agents and calf susceptibility. The economic losses is associated with death loss and treatment costs, reduction of live weight gain, and reduction of productive life span, which may be considerable. Thyroid hormones previously thought mainly in thermoregulation and energy metabolism. Recently, several studies have challenged on their roles in the metabolic response of animals to certain conditions such as nutritional, environmental, or disease state. The aim of the present study was to survey relationships between thyroid hormones in calves with diarrhea in the different clinical features. Holstein calves (50) within 1 day to 2 months old with signs of diarrhea and healthy calves (40) with similar age and sex were selected. Standard clinical examinations and also dehydration degree assessment were carried out on each calf and recorded accordingly. Calves with clinical signs of diarrhea were divided in different groups based on the severity of the clinical findings, fever and degree of dehydration. Blood samples were taken from the jugular vein from all calves into vacutainer tubes for serum collection.T4, fT4, T3 and fT3 concentrations were measured by validated methods. A significant increase in T4, T3 and fT3 in diarrheic calves was observed $(\mathrm{P}<0.05)$. Thyroid hormones in calves with severe clinical signs decreased significantly $(\mathrm{P}<0.001)$ compared to calves with moderate or mild systemic clinical signs. Thyroid hormones between febrile diarrheic calves compared to afebrile diarrheic calves had no significant changes. Diarrheic calves with severe dehydration compared to diarrheic calves with mild and moderate dehy- dration had significant decreases in their thyroid hormones $(\mathrm{P}<0.001)$.

\section{Introduction}

Growth of calves during their first few weeks of life is one of the most important factors affecting their performance during subsequent rearing, and it can be modified by disease, especially gastrointestinal infections. After the birth, calves are more prone to various diseases, including diarrhea that is the most serious and common cause of calves' weakening, as their immune system is not fully developed. Calves grow slower, lose weight, their immune system weakens and there is overall damage to the body due to illnesses. Financial losses arise not only from mortality, but also from the cost of medication and labor needed to treat sick calves. ${ }^{1}$ The main etiologic agents of diarrhea in dairy calves are Escherichia coli K99 (F5), Salmonella spp., rotavirus, coronavirus, and Cryptosporidium parvum. These pathogens cause specific enteric infections, resulting in secretory or malabsorptive diarrhea, along with inflammation of the intestinal epithelium.2 Sickness behavior is an integrated response to infection and inflammation, involving characteristic behavioral and physiological changes, including loss of appetite, somnolence, increased thermoregulatory behavior, and reduced social activity..$^{3,4}$ In the past the thyroid hormones were thought to influence mainly on thermoregulation and energy metabolism. T4 is the major circulating thyroid hormone which has a longer half-life than T3. T4 is changed to the active T3 and T3 is more potent than T4. Circulating fT3 and fT4 represent the amount of T3 and T4 that are not bound to proteins. Evaluating the fT3 and fT4 can be used to assess and manage disorders of the thyroid gland. 5 A direct clinical relevance was attributed to thyroid malfunctions almost exclusively in the companion animal (dog, cat) and horse medicine. Recently, however, several studies have confirmed their involvement in the metabolic response of animals to certain nutritional, environmental and/or diseaserelated challenges. ${ }^{6}$ In human during acute illness, circulating levels of total T3 (tT3) and free T3 (fT3) decrease. ${ }^{7}$ Prolonged critical illness is associated with abnormally low T4 serum concentrations. The proportion of the fall in T4 is shown to be related to the severity of illness and is a prognostic marker for adverse outcome in severely ill patients. ${ }^{8} \mathrm{~A}$ number of infectious and inflammatory (mainly endotoxin mediated) diseases are associated with obvious changes in thyroid status in mammals including domestic ruminants.9,10 The observed changes in thyroid hormone
Correspondence: Ali Hajimohammadi, Department of Clinical Sciences, School of Veterinary Medicine, Shiraz University, P.0. Box 71345-1731, Shiraz, Iran.

Tel.: +98.713 .613 .8825 ; Fax: +98.713 .228 .6940 .

E-mail: hajimohammadi@shirazu.ac.ir

Key words: Thyroid hormones; diarrheic calves; clinical signs.

Acknowledgements: this study was financially supported by the School of Veterinary Medicine, Shiraz University. Hormonal analysis was kindly performed with the cooperation of Professor Saeb Specialized Hormone Laboratory, Shiraz, Iran and the authors are grateful to Professor Maryam Ansari-Lari for the statistical analysis.

Contributions: the authors contributed equally.

Conflict of interest: the authors declare no potential conflict of interest.

Received for publication: 29 January 2015.

Revision received: 15 March 2015.

Accepted for publication: 24 March 2015.

This work is licensed under a Creative Commons Attribution NonCommercial 3.0 License (CC BYNC 3.0).

(C) Copyright A. Hajimohammadi et al., 2015 Licensee PAGEPress srl, Italy

Veterinary Science Development 2015; 5:5835 doi:10.4081/vsd.2015.5835

parameters during illness are often referred to as the low T3 syndrome. This so-called euthyroid sick syndrome consists of decreasing plasma concentration of the active thyroid hormone (T3) and, in severe cases, a reduction in thyroxin (T4) and thyroid stimulating hormone (TSH) concentrations. Other synonyms for the same condition are non-thyroidal illness (NTI) or euthyroid sick syndrome (ESS). 8,11 This article presents the results of a field study that compared the levels of circulating thyroid hormones in dairy calves with diarrhea in the different clinical features. For the purpose serum thyroxin (T4), free thyroxin (fT4), triiodothyronine (T3) and free triiodothyronine (fT3) were measured.

\section{Materials and Methods}

\section{Animals}

The study was conducted in a well managed large dairy farm milking about 3000 cows practicing almost standard nutritional management. The farm was located $70 \mathrm{~km}$ east of Shiraz, Fars province, Iran. Holstein calves $(\mathrm{n}=50)$ within 1 day to 2 months old with signs 
of diarrhea and healthy calves $(n=40)$ with the same age were selected as case and control groups, respectively.

\section{Clinical examination}

A clinical examination was conducted in calves with sign of diarrhea without any other diseases in which heart rate and respiratory rate were determined and rectal temperature was measured. Individual calf fecal consistency scores were assigned using a four-point scale ( $1=$ normal, firm stool; $2=$ soft, does not hold form; $3=$ runny, spreads easily; $4=$ liquid, devoid of solid matter), as described by Larson et al. ${ }^{11}$ Diarrhea was defined as a fecal score greater than 2 . Fecal scores of 3 and 4 were described as mild and severe diarrhea, respectively. At the naturally occurring onset of diarrhea, defined as the first occurrence of a fecal score greater than 2 , the calves were enrolled in the study. Rectal temperatures above 39.5 were recorded as febrile calves, presence or absence of suckling reflex were determined, and recumbent calves and shock signs, such as rapid heart rate, cold extremities, and weakness, were recorded. Also, dehydration degree were carried out on each calf and were assessed by tenting the skin of the lateral portion of the cervical region and by measuring the time required for the skin fold to return to normal based on Radostits et al. 12 Calves with clinical signs of diarrhea were divided in different groups based on the severity of the clinical findings, fever, and degree of dehydration. In claves with severe clinical signs, the calves were recumbent; without suckling reflex and the body temperature in almost cases were subnormal, the signs of endotoxemia were also seen in some cases. In mild clinical signs, the calves had only signs of diarrhea (fecal scores 3 or 4 ) without any abnormality in the other organs. In moderate clinical signs calves had fecal scores 3 or 4 with systemic clinical signs of diarrhea (depression, weakness) but still had suckling reflex and were not recumbent.

\section{Blood sampling}

Blood samples were taken from the jugular vein from all calves (control and case) in the same time in the first day of the disease into vacutainer tubes containing ethylenediaminetetraacetic acid (EDTA) for measuring hematological parameters and without EDTA for serum biochemical analysis. The sera were separated by centrifugation at $750 \times \mathrm{g}$ for $15 \mathrm{~min}$ and transferred to plastic tubes, capped, and stored at $-20^{\circ} \mathrm{C}$ until analyzed. The animals had not been treated for disease prior to sampling.

\section{Thyroid hormone determinations}

Serum T3 measured using a competitive enzyme immunoassay kit (Padtan Elm Co., Tehran, Iran). The intra- and inter-assay CVs of the assays were $12.6 \%$ and $13.2 \%$, respectively. The sensitivity of the test was 0.3 $\mathrm{nmol} / \mathrm{L}$. Serum T4 determined using a competitive enzyme immunoassay kit (Monobind Inc., Lake Forest, CA, USA). The intra- and interassay CVs of the assays were $3.0 \%$ and $3.7 \%$, respectively. The sensitivity of the test was 5 $\mathrm{nmol} / \mathrm{L}$. Serum fT3 and fT4 were determined by ELISA kits (DiaPlus Inc., San Francisco, CA, USA). The intra- and inter-assay CVs of the fT3 assays were $4.1 \%$ and $5.2 \%$, respectively. The sensitivity of the test was $0.07 \mathrm{pmol} / \mathrm{L}$. The intra- and inter-assay CVs of the fT4 assays were $4.5 \%$ and $3.7 \%$, respectively. The sensitivity of the test was $64.5 \mathrm{pmol} / \mathrm{L}$.

\section{Statistical analysis}

Data were presented as means \pm standard deviation (SD). Due to inequality of variances and non-normal distribution of data, to investigate any important changes in study groups, nonparametric Kruskal-Wallis and Mann-Whitney U test was used for statistical comparisons. Group differences were considered statistically significant at $\mathrm{P}<0.05$.

\section{Results}

Blood concentrations of thyroid hormones in calves with diarrhea and healthy calves are presented as mean \pm SD in Table 1 ; also thyroid hormones in diarrheic calves with different clinical signs are presented as mean \pm SD in Table 2. There was a significant difference in T4, T3 and fT3 between healthy and diseased calves so that higher values were observed in diarrheic calves $(\mathrm{P}<0.05)$. Calves with severe clinical signs of diarrhea had significant decreases in their T4, T3, fT3 and fT4 $(\mathrm{P}<0.001)$ as compared to calves with moderate or mild systemic clinical signs which these hormones decreased significantly from mild clinical signs of diarrhea to severe signs respectively $(\mathrm{P}<0.05)$. Febrile and afebrile diarrheic calves had a non-significant difference in their thyroid hormones. Also, diarrheic calves with severe dehydration compared to diarrheic calves with mild and moderate dehydration showed significant decreases in their T4, T3, fT3 and fT4 where these hormones decreased significantly from mild dehydration to severe dehydration respectively $(\mathrm{P}<0.05)$.

Table 1. Serum concentrations, mean \pm standard deviation of thyroid hormones in diarrheic and control calves.

\begin{tabular}{|c|c|c|c|c|c|}
\hline & N. & $\mathrm{T} 4(\mathrm{nmol} / \mathrm{L})$ & T3 (nmol/L) & fT4 (pmol/L) & fT3 (pmol/L) \\
\hline Normal calves & 40 & $55.0 \pm 7.7 \mathrm{a}$ & $1.6 \pm 0.7 \mathrm{a}$ & $1774 \pm 312$ & $6.9 \pm 1.4^{a}$ \\
\hline Diarrheic calves & 50 & $99.6 \pm 64.8^{b}$ & $4.7 \pm 3.1^{\mathrm{b}}$ & $2178 \pm 1311$ & $14.9 \pm 9.7 \mathrm{~b}$ \\
\hline
\end{tabular}

Different letters in each column show significant difference.

Table 2. Serum concentrations, mean \pm standard deviation, of thyroid hormones in diarrheic calves according to clinical examination.

\begin{tabular}{|c|c|c|c|c|c|}
\hline & N. & $\mathrm{T} 4$ (nmol/L) & T3 (nmol/L) & fT4 (pmol/L) & fT3 (pmol/L) \\
\hline $\begin{array}{l}\text { Fever** } \\
\text { Afebrile calves } \\
\text { Febrile calves }\end{array}$ & $\begin{array}{l}20 \\
30\end{array}$ & $\begin{array}{c}120 \pm 89 \\
85.9 \pm 36.9\end{array}$ & $\begin{array}{l}5.6 \pm 4.2 \\
4.1 \pm 2.1\end{array}$ & $\begin{array}{c}2568 \pm 1921 \\
1917 \pm 556\end{array}$ & $\begin{array}{c}16.5 \pm 13.9 \\
13.9 \pm 5.3\end{array}$ \\
\hline $\begin{array}{l}\text { Severity of clinical signs* } \\
\text { Mild clinical signs } \\
\text { Moderate clinical signs } \\
\text { Severe clinical signs }\end{array}$ & $\begin{array}{l}12 \\
24 \\
14\end{array}$ & $\begin{array}{c}170 \pm 80 \mathrm{a} \\
98.2 \pm 32.7 \mathrm{~b} \\
41.7 \pm 16.9 \mathrm{c}\end{array}$ & $\begin{array}{l}8.3 \pm 3.4^{a} \\
4.6 \pm 2.1^{b} \\
2.0 \pm 0.7 c\end{array}$ & $\begin{array}{l}3485 \pm 1939 \mathrm{a} \\
2045 \pm 584 \mathrm{~b} \\
1286 \pm 474 \mathrm{c}\end{array}$ & $\begin{array}{c}23.6 \pm 14.1^{\mathrm{a}} \\
14.1 \pm 5.7^{\mathrm{b}} \\
9.0 \pm 4.4^{\mathrm{c}}\end{array}$ \\
\hline $\begin{array}{l}\text { Dehydration* } \\
\text { Mild dehydration } \\
\text { Moderate dehydration } \\
\text { Severe dehydration } \\
\end{array}$ & $\begin{array}{l}13 \\
24 \\
13 \\
\end{array}$ & $\begin{array}{c}165 \pm 78 \mathrm{a} \\
95.9 \pm 33.5^{\mathrm{b}} \\
40.4 \pm 16.8 \mathrm{c} \\
\end{array}$ & $\begin{array}{l}8.0 \pm 3.4 \mathrm{a} \\
4.4 \pm 2.2^{\mathrm{b}} \\
2.0 \pm 0.7 \mathrm{c}\end{array}$ & $\begin{array}{l}3429 \pm 1867 \mathrm{a} \\
2004 \pm 566^{\mathrm{b}} \\
1247 \pm 469 \mathrm{c}\end{array}$ & $\begin{array}{c}22.9 \pm 13.8^{\mathrm{a}} \\
13.9 \pm 5.8^{\mathrm{b}} \\
9.0 \pm 4.5^{\mathrm{c}}\end{array}$ \\
\hline
\end{tabular}

*Different letters in each column show significant difference; **No significant difference was observed between groups. 


\section{Discussion and Conclusions}

Although thyroxine (T4) is the predominant thyroid hormone in the circulation, it has little inherent biological activity and it is commonly viewed as prohormone. The metabolically active thyroid hormone, triiodothyronine (T3), is produced by enzymatic $5^{\prime}$-deiodination of T4 within the thyroid and in extrathyroidal tissues (5). The extrathyroidal activity of thyroxine $5^{\prime}$-deiodinase $\left(5^{\prime} \mathrm{D}\right)$ is an important control point for regulating the thyroid status of animal tissues in various physiological and pathological situations. ${ }^{13}$ Thyrotropes of the anterior pituitary gland secrete thyroid stimulating hormone and this hormone regulates the production of T3 and T4 by follicular cells of the thyroid gland. This regulation by the hypothalamic pituitary thyroid (HPT)-axis is profoundly altered during inflammation, commonly known as the nonthyroidal illness syndrome (NTIS). NTIS is characterized by low serum thyroid hormone levels with inappropriate low serum thyroid stimulating hormone (TSH) levels, and is observed in a variety of pathologies ranging from acute inflammation to prolonged critical illness. ${ }^{8}$ In our study there was a significant difference in T4, T3 and fT3 between healthy and diseased calves so that diarrheic calves showed higher values. Alterations in thyroid hormone uptake by the cell and in the activity of the deiodinase enzymes which may decrease in the onset of diarrhea might be the reason of the unexpected increase in the thyroid hormones; the other reason for these increase, might be the time of sampling which was set to be the onset of first clinical sign of diarrhea (beginning of the illnesses) and before any treatment in these dehydrated calves. It is possible that in this phase thyroid hormones didn't decreases as much as in the course of the diseases. Although in diarrheic calves we observed a significant reduction in all thyroid hormones since the severity of clinical signs progressed and might be related to endotoxemia which were seen in our more severe cases. During the inflammatory process some of the cytokines (TNF $\alpha$, IL-1) are important mediators of changes in thyroid status. ${ }^{6,14,15}$ Endotoxin exposition is a strong stimulus for cytokine release, reducing the production and circulating level of T4 and inhibiting the T4 deiodination to T3 in many species, including lab rodents, $8,16,17$ humans,${ }^{8,16}$ and also ruminants. ${ }^{6,15,18,19}$ Almost all steps of thyroid hormone synthesis, secretion and peripheral metabolism may be negatively influenced by this endotoxin-induced cytokine release.8,16 However, direct administration of TNF- $\alpha$ and IL-6 had no effect on thyroid function. 20

In commercial large-scale dairy herds certain endotoxin-mediated disorders (acute putrid endometritis, endotoxin mastitis) are known to occur frequently in postpartum dairy cows. 15 However, up to now only limited data have been published on their interrelation with thyroid function. $6,15,19$ In our study in diarrheic calves with sever clinical signs; thyroid hormones were significantly decreased compared to calves with mild or moderate clinical signs of diarrhea. In our study we didn't focus on the cause of diarrhea but as we know almost the causes of diarrhea less than 2 months of age in dairy calves have inflammatory process.

In the acute phase of illness, thyroxine binding globulin (TBG) levels are also low and thus contribute to the low total serum T4 levels. ${ }^{21}$ Also in adult and pediatric patients with sepsis, TBG levels were shown to be low and related to low circulating T4. ${ }^{17}$ TNF $\alpha$ and IL-1 may inhibit the TSH release from pituitary cells and decrease the activity of thyroxine $5^{\prime}$-deiodinase $\left(5^{\prime} \mathrm{D}\right)$ in thyroid and liver tissues, ${ }^{7}$ reducing the production and circulating level of T4 and inhibiting the T4 transformation to T3.16 The decrease in $\left(5^{\prime} \mathrm{D}\right)$ activity in the liver of LPS-treated cows, which resulted in lower $\mathrm{T} 3 / \mathrm{T} 4$ ratio and declining plasma concentrations of thyroid hormones, was reported. 18 The results of the present study support the usefulness of thyroid hormones measurement in monitoring animal health and support the proposals made by other authors. $6,15,18$ Like other clinical signs, thyroid hormones levels are not suitable for establishing a specific diagnosis but can provide objective information about the extent of ongoing lesions in individual animals. Our results indicate that the comparison of circulating thyroid hormones in the different clinical features of calf diarrhea could improve our knowledge about diarrhea in dairy calves.

\section{References}

1. Constable P, Thomas E, Boisrame B. Comparison of two oral electrolyte solutions for the treatment of dehydrated calves with experimentally-induced diarrhoea. Vet $\mathrm{J}$ 2001;162:129-40.

2. Foster D, Smith GW. Pathophysiology of diarrhea in calves. Vet Clin North Am Food Anim Pract 2009;25:13-36.

3. Hart BL. Biological basis of the behavior of sick animals. Neurosci Biobehav Rev 1988;12:123-37.

4. Todd C, Millman S, McKnight D, et al. Nonsteroidal anti-inflammatory drug therapy for neonatal calf diarrhea complex: effects on calf performance. J Anim Sci 2010;88:2019.

5. Cunningham JG, Klein BG. Veterinary physiology. Philadelphia: Saunders Elsevier; 2007.

6. Huszenicza G, Kulcsar M, Rudas P. Clinical endocrinology of thyroid gland function in ruminants. Vet Med - Czech 2002;47:199-210.

7. Perello M, Friedman T, Paez-Espinosa V, et al. Thyroid hormones selectively regulate the posttranslational processing of prothyrotropin-releasing hormone in the paraven- tricular nucleus of the hypothalamus. Endocrinology 2006;147:2705-16.

8. Mebis L, Van den Berghe G. Thyroid axis function and dysfunction in critical illness. Best Pract Res Clin Endocrinol Metabol 2011;25:745-57.

9. Janosi S, Huszenicza G, Kulcsar M, Kóródi P. Endocrine and reproductive consequences of certain endotoxin-mediated diseases in farm mammals: a review. Acta Vet Hung 1998;46:71-84.

10. Lohuis JACM, Verheijden J, Burvenich C, Van Miert A. Pathophysiological effects of endotoxins in ruminants. Vet Q 1988; 10:109-16.

11. Larson L, Owen F, Albright J, et al. Guidelines toward more uniformity in measuring and reporting calf experimental data. J Dairy Sci 1977;60:989-91.

12. Radostits OM, Gay CC, Hinchcliff, KW, Constable PD. Veterinary medicine: a textbook of the diseases of cattle, horses, sheep, pigs and goats. Philadelphia: W.B. Saunders Elsevier 2007.

13. Bertók L. Endotoxins and endocrine system. Domest Anim Endocrinol 1998;15: 305-8.

14. Hashimoto $\mathrm{H}$, Igarashi N, Miyawaki T, Sato T. Effects of tumor necrosis factor- $\alpha$, interleukin-1 , and interleukin- 6 on type I iodothyronine $5^{\prime}$-deiodination in rat thyroid cell line, FRTL-5. J Interferon Cytokine Res 1995;15:367-75.

15. Huszenicza G, Jánosi S, Gáspárdy A, Kulcsár M. Endocrine aspects in pathogenesis of mastitis in postpartum dairy cows. Anim Reprod Sci 2004;82:389-400.

16 Bartalena L, Bogazzi F, Brogioni S, et al. Role of cytokines in the pathogenesis of the euthyroid sick syndrome. Eur J Endocrinol 1998;138:603-14.

17. den Brinker M, Joosten KF, Visser TJ, et al. Euthyroid sick syndrome in meningococcal sepsis: the impact of peripheral thyroid hormone metabolism and binding proteins. $\mathrm{J}$ Clin Endocrinol Metabol 2005;90: 5613-20.

18. Kahl S, Elsasser T, Blum J. Effect of endotoxin challenge on hepatic $5^{\prime}$-deiodinase activity in cattle. Domest Anim Endocrinol 2000;18:13343.

19. Todini L. Thyroid hormones in small ruminants: effects of endogenous, environmental and nutritional factors. Animal 2007;1: 9971008.

20. Boelen A, Platvoet-ter Schiphorst M, Bakker 0, Wiersinga $\mathrm{W}$. The role of cytokines in the lipopolysaccharideinduced sick euthyroid syndrome in mice. J Endocrinol 1995;146:475-83.

21. Afandi B, Schussler G, Arafeh A, et al. Selective consumption of thyroxine-binding globulin during cardiac bypass surgery. Metabolism 2000;49:270-4. 